\title{
A EDUCAÇÃO AMBIENTAL QUE SE APRENDE NA LUTA COM OS MOVIMENTOS SOCIAIS: DEFENDENDO O TERRITÓRIO E RESISTINDO CONTRA O DESENVOLVIMENTISMO CAPITALISTA
}

\author{
Philippe Pomier Layrargues ${ }^{1}$ \\ Cleonice Puggian ${ }^{2}$
}

\begin{abstract}
Resumo
Apresentamos uma síntese dos debates realizados em torno do Grupo de Discussão de Pesquisa (GDP) em Educação Ambiental e Movimentos Sociais, transcorridos no IX Encontro de Pesquisa em Educação Ambiental (EPEA), realizado na Universidade Federal de Juiz de Fora, em 2017. O artigo foi organizado em três seções: iniciamos, apresentando o perfil dos treze trabalhos recebidos pelo GDP, destacando suas contribuições para o campo da Educação Ambiental. Na segunda seção, descrevemos as temáticas que emergiram no encontro presencial do GDP, indicando as especificidades de uma Educação Ambiental a partir dos Movimentos Sociais. Na última seção, exploramos alguns signos que podem contribuir com a compreensão do perfil da Educação Ambiental a partir dos Movimentos Sociais: a centralidade da Justiça Ambiental no conjunto do repertório temático explorado pela Educação Ambiental, a renovação do compromisso da macrotendência político-pedagógica Crítica com o estabelecimento de vínculos solidários com os Movimentos Sociais, a Pedagogia da Resistência como a ideia-força estruturante da Educação Ambiental realizada pelos Movimentos Sociais, o amadurecimento do recente campo de pesquisa específico da análise da relação entre Educação Ambiental e Movimentos Sociais, a noção de Direitos Humanos como uma contribuição dos Movimentos Sociais que enriqueceu a práxis da Educação Ambiental e, reciprocamente, o desvelamento das silenciadas lutas dos Movimentos Sociais como a colaboração da Educação Ambiental; finalmente, a perspectiva que se abre com o potencial diálogo entre a Educação Ambiental e a Geografia Crítica, apontando para novas convergências na Ecologia Política.
\end{abstract}

Palavras-chave: Educação Ambiental. Movimentos Sociais. Ecologia Política. Justiça Ambiental. Território.

\section{THE ENVIRONMENTAL EDUCATION THAT IS LEARNED IN THE STRUGGLE WITH THE SOCIAL MOVEMENTS: DEFENDING THE TERRITORY AND RESISTING AGAINST THE CAPITALIST DEVELOPMENTISM}

\footnotetext{
Abstract

We present a summary of the debates held around the Research Discussion Group (GDP) in Environmental Education and Social Movements, held at the IX Environmental Education Research Meeting (EPEA), held at the Federal University of Juiz de Fora in 2017. The article was organized into three sections: we began by presenting the profile of the thirteen papers

${ }^{1}$ Professor Doutor do Curso de Gestão Ambiental da Universidade de Brasília (UnB). philippe.layrargues@gmail.com

${ }^{2}$ Professora Pós-Doutora da Faculdade de Formação de Professores da Universidade do Estado do Rio de Janeiro (UERJ) e do Programa de Pós-Graduação Interdisciplinar em Humanidades, Culturas e Artes da Universidade do Grande Rio (UNIGRANRIO). cleo.puggian@gmail.com
} 
received by GDP, highlighting their contributions to the field of Environmental Education. In the second section we describe the themes that emerged in the face-to-face meeting of the GDP, indicating the specificities of an Environmental Education from the Social Movements. In the last section, we explored some signs that can contribute to the understanding of the profile of Environmental Education from the Social Movements: the centrality of Environmental Justice in the set of thematic repertoire explored by Environmental Education, the renewal of the commitment of political-pedagogical macro-tendency Critique solidary with Social Movements, Resistance Pedagogy as the structuring idea of Environmental Education carried out by the Social Movements, the maturation of the recent field of specific research in the analysis of the relationship between Environmental Education and Social Movements, the notion of Human Rights as a contribution of the Social Movements that enriched the praxis of Environmental Education and, conversely, the unveiling of the silenced struggles of Social Movements as the collaboration of Environmental Education; and finally, the perspective that opens with the potential dialogue between Environmental Education and Critical Geography, pointing to new convergences in Political Ecology.

Keywords: Environmental Education. Social Movements. Political Ecology. Environmental Justice. Territory.

\section{LA EDUCACIÓN AMBIENTAL QUE SE APRENDE EN LA LUCHA CON LOS MOVIMIENTOS SOCIALES: DEFENDIENDO EL TERRITORIO Y RESISTIENDO CONTRA EL DESARROLLISMO CAPITALISTA}

\section{Resumen}

Se presenta una síntesis de los debates realizados en torno al Grupo de Discusión de Investigación (GDP) en Educación Ambiental y Movimientos Sociales, transcurridos en el IX Encuentro de Investigación en Educación Ambiental (EPEA), realizado en la Universidad Federal de Juiz de Fora, en 2017. Se organizó en tres secciones: iniciamos presentando el perfil de los trece trabajos recibidos por el GDP, destacando sus contribuciones al campo de la Educación Ambiental. En la segunda sección, describimos las temáticas que emergieron en el encuentro presencial del GDP, indicando las especificidades de una Educación Ambiental a partir de los Movimientos Sociales. En la última sección, exploramos algunos signos que pueden contribuir con la comprensión del perfil de la Educación Ambiental a partir de los Movimientos Sociales: la centralidad de la Justicia Ambiental en el conjunto del repertorio temático explotado por la Educación Ambiental, la renovación del compromiso de la macrotendencia político-pedagógica Crítica con el establecimiento de vínculos solidarios con los Movimientos Sociales, la Pedagogía de la Resistencia, como la idea-fuerza estructurante de la Educación Ambiental realizada por los Movimientos Sociales, la maduración del reciente campo de investigación específico del análisis de la relación entre Educación Ambiental y Movimientos Sociales, la noción de Derechos Humanos como una contribución de los Movimientos Sociales que enriqueció la praxis de la Educación Ambiental y recíprocamente el desvelamiento de las silenciadas luchas de los Movimientos Sociales como la colaboración de la Educación Ambiental y, finalmente, la perspectiva que se abre con el posible diálogo entre la Educación Ambiental y la Geografía Crítica, apuntando a nuevas convergencias en la Ecología Política.

Palabras clave: Educación Ambiental. Movimientos Sociales. Ecología Política. Justicia Ambiental. Territorio. 
A interpelação à ideologia do desenvolvimento, estejam-lhe acoplados ou não os termos 'sustentável' e 'humano', é para mim uma das tarefas essenciais de nosso tempo Jean Pierre Leroy ${ }^{3}$ (2010).

\section{Introdução}

Em agosto de 2017, nas instalações da Universidade Federal de Juiz de Fora, foi realizada a IX edição do Encontro de Pesquisa em Educação Ambiental (EPEA), evento que reúne educadores ambientais em torno da investigação científica do campo da Educação Ambiental. Como de costume, a sistemática do evento contou com os consagrados Grupos de Discussão de Pesquisa (GDP), organizados em oito temáticas (Questões Epistemológicas, Questões Metodológicas, Culturas, Políticas Públicas, Movimentos Sociais, Formação de Professores, Contexto Escolar, Contextos Não Escolares), que, nesta edição, realizaram suas atividades problematizando o contexto temático central da relação entre Democracia, Políticas Públicas e Práticas Educativas.

Este relato aborda os sentidos do GDP Educação Ambiental e Movimentos Sociais, que caracterizam um perfil particular do que representou a reflexão acerca da relação entre Educação Ambiental e Movimentos Sociais nessa IX edição do EPEA, e apresenta-se em três blocos. O primeiro traz uma breve descrição dos treze trabalhos submetidos e apresentados pelos respectivos autores ao Grupo de Discussão de Pesquisa em Educação Ambiental e Movimentos Sociais do IX Encontro de Pesquisa em Educação Ambiental. O segundo bloco aborda a dinâmica do debate, propriamente dito, que transcorreu nas duas tardes de encontro presencial do GDP, momento em que se buscou o aprofundamento do debate temático. $\mathrm{O}$ terceiro bloco apresenta considerações analíticas sobre a especificidade da relação entre a Educação Ambiental e os Movimentos Sociais, que se expressou no GDP.

\section{Perfil dos trabalhos do GDP Educação Ambiental e Movimentos Sociais}

O artigo Educação Ambiental e Audiência Pública sobre Coleta Seletiva e Reciclagem do Resíduo Óleo Vegetal em Alegre - ES, de Mariana Spala e Anderson Lopes Peçanha (2017), teve como horizonte a proposição de práticas para uma gestão adequada do óleo vegetal comestível usado em Alegre (ES), município que não possui coleta seletiva desse resíduo, com o intuito de minimizar os impactos ambientais decorrentes do seu descarte inadequado.

Para uma audiência pública sobre Gestão dos Resíduos Sólidos, foram convidados representantes da Associação Comercial, Industrial e de Serviços de Alegre, da associação de moradores dos bairros e associação de produtores rurais do município de Alegre, setores da Prefeitura Municipal de Alegre, Faculdade de Filosofia, Ciências e Letras de Alegre, Instituto Federal do Espírito Santo, além da Universidade Federal do Espírito Santo e escolas do município. Houve a participação de professores, alunos e servidores da universidade, representantes da sociedade civil, como membros da associação de moradores dos bairros e igreja, bem como servidores da Prefeitura Municipal de Alegre, em especial da Secretaria

\footnotetext{
${ }^{3}$ Educador Ambiental Popular, falecido em novembro de 2016, recebeu o Prêmio João Canuto de Direitos Humanos em 2009, fruto do seu trabalho como relator para o Direito Humano ao Meio Ambiente e de sua atuação como membro fundador da Rede Brasileira de Justiça Ambiental.
} 
Municipal de Agricultura e Meio Ambiente. Os participantes interagiram durante a audiência e sugeriram ações práticas que contribuem para a coleta seletiva dos resíduos sólidos e do resíduo de óleo vegetal comestível em Alegre.

Posteriormente, foram confeccionados materiais educativos sobre lixo seco e úmido, bem como sobre o óleo vegetal usado, a fim de sensibilizar a comunidade sobre a importância da coleta seletiva e reciclagem dos resíduos sólidos, em geral, e do resíduo de óleo vegetal comestível, em particular, além de propor alternativas sustentáveis para o destino desse resíduo, como a produção de sabão realizada pelos membros da Associação de Coletores de Materiais Recicláveis de Alegre e, assim, contribuir com a inclusão social e econômica dos associados. O material foi divulgado em estabelecimentos comerciais, igrejas e escolas do centro de Alegre, além do campus Alegre da Universidade Federal do Espírito Santo.

Os autores atestam que considerar uma audiência pública como um recurso pedagógico, proporciona a aproximação entre a sociedade e o poder público. Isto ocorre, pois os participantes, ao manifestarem suas ideias e pontos de vista, estabelecem novas formas de diálogo com os representantes da Secretaria Municipal de Meio Ambiente e Agricultura de Alegre, tendo em vista as soluções quanto aos problemas dos resíduos sólidos, especialmente quanto ao óleo vegetal usado. Por fim, os autores destacam que se faz necessária a realização de mais audiências públicas, a fim de sensibilizar e promover a participação ativa do cidadão no espaço público, uma vez que compreende um direito individual garantido por lei, de avaliar, propor sugestões e colaborar com as decisões públicas. Além disso, torna-se uma oportunidade de ouvir a sociedade, informar sobre o assunto resíduos sólidos e mobilizar mais pessoas para a coleta seletiva, reciclagem e conservação dos recursos naturais.

O trabalho intitulado Educação Ambiental e Movimentos Sociais: um contributo ao enraizamento da Educação Ambiental na cidade de Vitória/ES, de Sirlene Dias Araújo, Antonio Donizetti Sgarbi e Maria das Graças Ferreira Lobino (2017), parte da problematização da ideia de que a formação de educadores ambientais também pode ser realizada em espaços não formais de educação, como o espaço público urbano. Nesse sentido, os autores analisaram o Projeto Alfabetização Científica no Contexto da Cidadania Socioambiental, desenvolvido na cidade de Vitória (ES), no ano de 2016. Coordenado pela Secretaria de Estado de Ciência, Tecnologia Inovação, Educação e Trabalho, em parceria com o Instituto Federal de Educação Ciência e Tecnologia do Espírito Santo e a Secretaria Municipal de Educação, o projeto visou despertar a valorização do pertencimento local e o envolvimento comunitário na defesa dos lugares ameaçados, por meio do desenvolvimento da compreensão mais acurada sobre a cidade.

Os autores ressaltam que essa perspectiva formativa pode promover a formação do cidadão, não apenas cientificamente alfabetizado, mas também crítico, atuante como um agente ambiental na lógica da transformação social. Sinalizam, como exemplo, a criação do monitoramento ambiental cidadão do rio que abastece a população, efetuado pela própria comunidade que teve seu sentido de pertencimento aguçado, assimilando novas formas de mobilização social na defesa ambiental potencializada.

O trabalho Os megaeventos na cidade do Rio e Janeiro e a Educação Ambiental: reflexões a partir dos impactos e conflitos gerados pelas disputas territoriais, de Miguel Tiriba Schlesinger, Jesús Jorge Pérez Garcia e Luciana da Silva Mayrink (2017), objetiva refletir acerca dos conflitos socioambientais na cidade do Rio de Janeiro, sobretudo aqueles relacionados direta ou indiretamente aos megaeventos, mediante perspectiva analítica da Educação Ambiental.

Os autores partem do pressuposto de que a realização sistemática de megaeventos na cidade, nos últimos anos, acentuou a disputa territorial e sustentam que, ao contrário das 
promessas da sustentabilidade acenadas como um importante legado dos megaeventos, as intervenções urbanas foram marcadas por inúmeras violações ambientais. Concluindo que a realização dos megaeventos contribuiu para o agravamento das injustiças socioambientais no Rio de Janeiro, os autores salientam que foi possível observar que a relação entre o poder público e as grandes corporações prejudicou, ainda mais, as camadas desfavorecidas da sociedade. Por fim, os autores avaliam que toda tentativa de requalificação urbana deve partir da concepção de que a cidade pertence ao indivíduo, deve proporcionar conforto urbano e deve estabelecer um olhar integral sobre o ambiente em suas dimensões físicas, socioculturais e biopsicossociais, nas quais estariam inseridas as estratégias que fundamentam o senso de pertencimento comunitário e bem-estar social.

Entretanto, os autores lamentam constatar tanto a crescente ausência de debates públicos que contemplem a maioria da população, como a falta de transparência e horizontalidade nas decisões do poder público.

$\mathrm{O}$ artigo Educação Ambiental, direito à moradia e à cidade e Movimentos Sociais, o exemplo do Rio de Janeiro, de Bárbara Fortes Campos (2017), analisa a relação da Educação Ambiental com o contexto do direito à cidade e à habitação, a partir da observação dos Movimentos Sociais surgidos na luta contra o processo de estruturação urbana orientado pelo mercado, na cidade do Rio de Janeiro, mas em particular, contra os megaeventos esportivos recentemente sediados pelo município.

Em função dos conflitos socioambientais deles decorrentes, causados pela acentuada valorização urbana que transformou áreas antes ocupadas por comunidades vulneráveis ou comunidades tradicionais, em ativos financeiros para o Estado, a autora avalia que a reorganização e apropriação do espaço urbano, orientada pelo mercado, resultou na violação do direito à moradia, e aqueles que perderam suas casas foram marginalizados, obrigados a se deslocar para áreas periféricas e de risco.

A autora compreende os processos desenvolvidos por esses movimentos sociais como um importante espaço educador, simultaneamente de construção de conhecimento e de reafirmação de direitos. É onde se delineia uma pedagogia de resistência urbana, (CAMPOS, 2017) com a percepção do território como um espaço de aprendizagem com uma experiência educativa singular, que reivindica e exerce seus direitos pela democratização do acesso à cidade. $\mathrm{O}$ aprendizado do direito à cidade é indispensável como experiência educativa no espaço urbano; ocorre, por exemplo, pela reivindicação por moradia, escola, lazer, arborização, entre outros. A autora salienta que esses processos educativos não formais da pedagogia da resistência urbana buscam conquistar autonomia e emancipação popular, bem como o exercício da cidadania, democracia e direitos.

Considerando que existem disputas ideológicas no campo da Educação Ambiental, e que é necessário superar a visão hegemônica que se baseia nas tendências conservadoras e comportamentalistas, o trabalho Os observatórios de conflitos ambientais como instrumentos pedagógicos para fortalecer práticas e pesquisas em Educação Ambiental, de Anne Kassiadou, Celso Sánchez e Daniel Renaud (2017), analisa o uso de ferramentas pedagógicas e metodológicas disponíveis na Educação Ambiental. Afirmam os autores que é comum identificar ações e discursos na Educação Ambiental que optam por não debater a dimensão dos conflitos ambientais, ignorando o princípio da justiça social, um dos fundamentos da sustentabilidade.

Kassiadou, Sánchez e Renaud (2017), explanam, ainda, que essa omissão da problematização resulta no apagamento tanto da situação conflituosa como dos atores sociais envolvidos no conflito, contribuindo com o enfraquecimento da dimensão política na Educação Ambiental. Assim, estabelecendo um diálogo entre a Educação Ambiental e a 
Ecologia Política para compreender o potencial pedagógico inerente dos conflitos ambientais, os autores analisaram os Observatórios de Conflitos Ambientais. Argumentam os autores, que essas ferramentas de controle social do campo da Justiça Ambiental que expõem os casos concretos em um dado território, podem ser consideradas, também, como ferramentas pedagógicas no campo da Educação Ambiental, dentro da perspectiva da realização do Diagnóstico Ambiental Local, um instrumento pedagógico muito comum em projetos de Educação Ambiental, mas que normalmente envolve apenas uma caracterização fria da ocupação territorial e os impactos ambientais, sem os sujeitos e suas posições sociais.

Os autores afirmam que esse olhar enriquece a leitura da realidade socioambiental naquele território, de forma a permitir o reconhecimento das diferentes formas de utilização e distribuição dos bens naturais existentes, mediadas pelas relações de poder, bem como o protagonismo dos sujeitos envolvidos nos conflitos como sujeitos produtores de conhecimentos, além das estratégias de enfrentamento nos processos emancipatórios de construção de direitos. Salientam, ainda, que a adoção dos Observatórios de Conflitos Ambientais pela Educação Ambiental representa um valioso recurso político-pedagógico, porque possibilita que grupos e povos historicamente injustiçados e, por vezes, criminalizados, ganhem visibilidade e respaldo político. Afinal, a territorialidade e a conflituosidade ambiental assumiriam a centralidade necessária para fazer emergir as temáticas de Justiça e Racismo Ambiental, entre outras demandas dos movimentos sociais. E na medida em que a Educação Ambiental se aproxima desse olhar, amplia-se o debate acerca da dimensão política da Educação Ambiental assim como do seu potencial crítico e emancipatório (KASSIADOU; SÁNCHEZ; RENAUD, 2017).

O trabalho Educação Ambiental Decolonial de Base Comunitária: a Pedagogia dos afetados pelo setor da mineração, de Marcelo Aranda Stortti e Celso Sánchez (2017), investiga o perfil da Educação Ambiental desenvolvida pelo Movimento Social denominado Justiça nos Trilhos, que luta contra os megaempreendimentos da cadeia produtiva da mineração. Conferiram que os militantes desse grupo produzem diversos processos pedagógicos que se relacionam com a lógica da Decolonialidade, pois além da articulação internacional com outras instituições, também organizam seminários, produzem livros, revistas, cartilhas, documentários e realizam marchas com danças e músicas de protesto, cartazes e palavras de ordem.

Dessa constatação, os autores empreendem uma reflexão que explicita a existência de um imbricamento dos pressupostos da Educação Ambiental Crítica com a Decolonialidade, pois ambos efetuam a crítica ao modelo societário atual e às relações de dominação e opressão que constituem a atual sociedade, e elaboram interpretações semelhantes da realidade social. Ambos refletem sobre as relações de poder nas disputas relacionadas ao processo de expropriação da terra e da espoliação dos bens comuns provocados pelo neoextrativismo contemporâneo (STORTTI; SÁNCHEZ, 2017).

Mas trata-se, também, do contorno de uma Educação Ambiental Comunitária, sinalizam os autores, que possui relações com a Ecologia Política, com a Geografia Política, com o Racismo Ambiental e com a pedagogia freireana.

Stortti e Sánchez (2017) afirmam que os sujeitos históricos do movimento Justiça nos Trilhos podem ser compreendidos como pertencentes ao campo da Educação Ambiental Crítica, pois também se educam e educam-se entre si na sua luta por direitos, nos seus processos de tomada de consciência de seu lugar na história, evidenciando a compreensão das condições concretas em que ocorre a exploração e expropriação de seus territórios e controle de suas subjetividades, permitindo-os compreender a dimensão da opressão ambiental que se descortina em seus territórios, e possibilitando-os promover a ambientalização das suas lutas. 
Sugerem, inovadoramente, um novo termo que represente esse entrelaçamento, a Educação Ambiental Decolonial de Base Comunitária.

$\mathrm{O}$ trabalho A justiça e o racismo ambiental diante do rompimento da Barragem de Fundão (Mariana - MG): a educação ambiental de base comunitária e os movimentos sociais diante da problemática econômica e ambiental em torno da mineração, de Mahalia Gomes de Carvalho Aquino, Yashmin Viola Marote Loureiro e Marcelo Aranda Stortti (2017), explora a relação do rompimento da barragem de rejeitos da mineração no município de Mariana(MG) com a Educação Ambiental emergente das lutas socioambientais na região afetada. Os autores esclarecem que, além de todo o desastre ambiental ao longo da calha do rio Doce até o oceano, ocorreu também uma transformação radical no modo de vida de grupos sociais que possuíam um vínculo de pertencimento com o rio, como os ribeirinhos, pescadores, agricultores familiares e o povo indígena Krenak: os rejeitos atingiram, em maior proporção, as áreas onde habitam grupos compostos majoritariamente de negros ou pardos, caracterizando um quadro do Racismo Ambiental.

Os autores advertem que, na análise político-pedagógica dos conflitos socioambientais, é fundamental promover a compreensão de que o controle sobre os recursos naturais é um elemento indispensável para assegurar o atual padrão de acumulação do capital, e que tal crime ambiental é consequência de um modelo neodesenvolvimentista de produção em escala mundial e dependente da extração mineral, o que explicita a subordinação dos países tidos como periféricos às multinacionais. O desastre mobilizou o Movimento dos Atingidos por Barragens, Movimento dos Pequenos Agricultores, Movimento dos Sem-Terra, Movimento Nacional dos Pescadores e das Pescadoras, a Igreja Católica, entre outros. Foi criado, também, o Fórum Capixaba de Entidades em Defesa da Bacia do Rio Doce, que objetiva mobilizar a sociedade civil para cobrar a reparação dos danos causados, e é composto por oitenta instituições responsáveis pelo monitoramento do poder público e da mineradora na mitigação dos impactos socioambientais.

Aquino, Loureiro e Stortti (2017) argumentam que os sujeitos políticos dos Movimentos Sociais ligados às lutas socioambientais podem ser entendidos, também, como sujeitos pedagógicos, que se educam a sua própria maneira. Eles implementam ações educativas diferentes, como agentes de outras experiências sociais, saberes e epistemologias.A categoria de "atingido", "condenado", "oprimido ambiental" enuncia um processo educativo que se coaduna com a Educação Ambiental Crítica e com a Pedagogia do Oprimido, do Conflito, da Emancipação.

Com essa análise foi possível identificar um processo educativo que emergiu desse conflito, na busca de um enfrentamento desse modelo eurocêntrico racial-colonial, que pode ser denominado Decolonial, pois promove uma mudança cultural interligada a uma transformação socioeconômica contra-hegemônica pelas suas características e comprometimento com uma luta em defesa de seu modo de viver que se inscreve fora do desenvolvimentismo.

$\mathrm{O}$ artigo $A$ existência em pauta: uma problematização a partir do crime socioambiental na bacia do rio Doce, de Rosinei Ronconi Vieiras, Bruna Neitzel Sepulcri e Martha Tristão (2017), problematiza a ideia de desenvolvimento que prioriza o econômico em detrimento do humano e do não humano, indagando-se: que possibilidades existem diante de um cenário político-econômico controlado pelo capital das grandes corporações? Como vislumbrar outras possibilidades diante desse cerco generalizado produzido pelo capital? Como engendrar outros arranjos coletivos e produtivos que não estejam subordinados à lógica perversa, predatória e excludente do capital? Para isso, as autoras ressignificaram a noção de maior e menor, de Deleuze e Guattari (1996), correlacionando o desenvolvimentismo 
produzido pelo capitalismo à noção de maior, por representar hegemonia nas relações assimétricas de poder, e correlacionando os outros modos de existência, com diferentes modos de se relacionar com o território e a natureza, com a noção de menor.

Vieiras, Sepulcri e Tristão (2017) argumentam que, mesmo não destronando o mercado globalizado com sua lógica do lucro a qualquer custo, esses outros modos de vida produziram desvios, pequenas resistências, mesmo que minúsculas. Essas formas menores não reivindicam superioridade, apenas existência. Uma minoria, portanto, não se define pelo seu número/quantidade, mas pelo seu desvio em relação ao padrão, ao modelo. Mesmo se esses modos minúsculos e menores de existir não tenham sido capazes de imprimir outra lógica de produção e de relações; ao mesmo tempo, o modelo hegemônico maiúsculo e maior mostrou seus limites: a incapacidade de prover um mundo acessível a quem precisa, com o abismo da desigualdade reduzido, a vida nas suas diferentes manifestações valorizada, os ciclos vitais dos ecossistemas respeitados, a ganância financeira controlada. As autoras afirmam que essa problematização se constitui como um instrumento pedagógico valioso, que ressalta os limites intrínsecos do desenvolvimentismo.

É nesse sentido que se faz pertinente um movimento de reapropriação do território. Uma reapropriação que é, ao mesmo tempo, uma reinvenção existencial, ou ainda, a reapropriação da própria vida, ou das condições para sua manutenção com dignidade.

O capitalismo, nos últimos anos, demonstrou sua capacidade adaptadora e agenciadora, não mais apenas da força, mas também da inteligência e das ideias, por meio da cooptação, sedução, fragmentação e captura. Na conjuntura do crime ambiental ocorrido em Mariana (MG), Vieiras, Sepulcri e Tristão (2017) destacam a ênfase midiática, governamental e jurídica dada a importância financeira da empresa responsável pelo crime. Ignoram-se outras instâncias menores de possibilidades de vidas, o meio ambiente e seus bens naturais em prol do discurso da necessidade de geração de emprego e renda. O reforço do sistema é recompensado pela crise, muitas vezes produzida e necessária para manutenção do status quo na medida em que reforça uma suposta necessidade das corporações continuarem suas atividades e, o que é pior, sem nenhuma responsabilização realmente comprometida com o espaço e a comunidade em que atuam.

As autoras enfatizam que o maior crime socioambiental do Brasil também coloca em cheque a existência de todos enquanto cidadãos, afinal somos desconhecedores das negociações oficiais, dos reais impactos físico-químicos e biológicos desse crime e dos projetos para mitigação dos impactos. Para a mídia, parece que somos apenas telespectadores de informações camufladas; se o discurso propagado é o da necessidade de retorno das operações da empresa e de sua imprescindível presença para os estados e municípios em que atua, o mesmo - ao menos da mesma forma e com toda essa ênfase - não pode ser dito pelos movimentos sociais e pelas minorias que sofreram com o impacto do crime por ela provocado.

O artigo Povos tradicionais caiçaras e a demanda pela educação escolar: aproximações com a educação ambiental crítica, de Vanessa Marcondes de Souza e Carlos Frederico Bernardo Loureiro (2017), averigua a relação entre a educação demandada pelos caiçaras no município de Paraty (RJ) e a Educação Ambiental Crítica. Apesar das suas atividades laborais tradicionais estarem intimamente relacionadas à biodiversidade local, da qual dependem para a reprodução material e cultural, os caiçaras possuem diferentes graus de contato e dependência dos centros urbanos; portanto, nessa interação, sofrem influência das relações socioeconômicas da cultura hegemônica capitalista. Nesse quadro, a necessidade de assegurar o modo de vida tradicional implica em novas estratégias de resistência, como a 
demanda por educação escolar, que se torna necessária como condição objetiva de existência desses povos.

Os caiçaras se viram expropriados dos seus territórios tradicionais com a construção da BR-101 (trecho Rio-Santos), nas décadas de 1960 e 1970. A estrada propiciou grandes transformações socioeconômicas na região, ao possibilitar a expansão do modo de vida e produção capitalista, trazendo a especulação imobiliária e a exploração turística, além de grandes projetos de infraestrutura produtiva. Como resultado desse processo, não só o modo de vida tradicional foi se tornando inviável, como muitos caiçaras foram expulsos de seus territórios.

A expropriação dos trabalhadores e sua separação das condições de produção é a condição fundamental para transformar o conjunto da existência social numa forma subordinada ao capital e, assim, os territórios tradicionais são convertidos em terras mercantilizáveis e os caiçaras servem de mão de obra barata para as classes dominantes, que continuam a comandar a cidade, privatizando praias, sucateando os direitos sociais, controlando e aparelhando os espaços de participação social e dificultando a vida daqueles que resistem e permanecem no território tradicional.

Os caiçaras se educam em comunidade por meio da realização do seu trabalho tradicional. As crianças interagem cotidianamente com a realização das atividades laborais dos adultos, brincando ao redor das cordas, redes e peixes, carregando materiais leves ou ajudando na execução de algumas tarefas, como a separação dos peixes. Nessa convivência rotineira, aprendem o trabalho da cultura caiçara e tornando-se adultos, tornam-se caiçaras que conhecem a dinâmica do mar e da mata, sabem pescar, caçar, roçar, fazer canoa, cestaria, entre outras atividades da sua organização sociocultural. Assim, ao exercerem seus trabalhos, na relação com a natureza, os caiçaras se educam, formam a sua identidade, elaboram suas relações com a natureza, o território e as tradições.

Entretanto, a partir do momento em que o modo de vida urbano-industrial e as relações econômicas mercantis começam a influenciar o modo de vida caiçara, criam-se novas necessidades e muda-se o entendimento e significado da educação. Assim, embora os caiçaras trabalhem desde crianças com a pesca e possuam conhecimentos práticos sobre as condições de navegabilidade, somente com a habilitação para a condução de embarcações (cuja obtenção está atrelada a um curso teórico com exigência de conhecimentos de português e matemática), podem trabalhar legalmente no seu próprio barco. Dessa forma, o conhecimento torna-se um mecanismo de opressão, onde o saber tradicional caiçara é desprezado, pois se prioriza o conhecimento hegemônico legitimado por um certificado de escolarização e, com isso, se estabelece uma hierarquia onde se constroem preconceitos.

Na Península da Juatinga existem somente cinco escolas em funcionamento que, até o ano de 2010, ofereciam somente o primeiro ciclo do ensino fundamental de forma multisseriada. Essas escolas estão localizadas nas regiões de mais fácil acesso e se organizam a partir da lógica urbana, não sendo construídas com a comunidade; assim, a organização da escola se sobrepõe às épocas produtivas de pesca, roça, caça, e os estudantes precisam escolher entre participar das atividades tradicionais com a família ou estudar.

A política pública de educação escolar aqui não contempla as relações socioculturais das comunidades caiçaras, comprometendo sua formação identitária. Se antes a estratégia predominante de forças sociais dominantes era a expulsão das populações caiçaras de seus territórios, atualmente o processo ocorre por meio da negação dos seus direitos. Assim, a educação formal, mas diferenciada da hegemônica, torna-se uma demanda essencial na busca por justiça social e ambiental, uma vez que a mera ausência de escolas nos territórios tradicionais favorece a expulsão dos caiçaras. E ao migrarem para regiões com escolas - em 
busca desse direito negado - perdem o direito de reivindicar seus territórios tradicionais, comprometendo, ainda mais, sua luta.

$\mathrm{O}$ artigo A formação de educadores do campo em educação ambiental: a importância da formação continuada de educadores ambientais campesinos na UFMT, de Elizana Monteiro dos Santos (2017), destaca a importância da internalização da Educação Ambiental nas Escolas do Campo, ao analisar o curso de especialização em Educação Ambiental Campesina da Universidade Federal do Mato Grosso, elaborado numa perspectiva freiriana e fenomenológica, e realizado em parceria com o Movimento dos Trabalhadores Rurais Sem Terra. A autora recorda que o camponês possui uma característica particular de produção e reprodução da vida: é a relação com a terra e o trabalho na agricultura que define a agricultura camponesa; onde o campo, a cultura e a terra são partes integrantes da vida familiar. É no acesso à terra, e com a realização do trabalho junto aos recursos naturais, que a família camponesa supre suas necessidades e se reproduz social e culturalmente.

A seguir, Santos (2017) registra que a realidade opressora e excludente da educação convencional, ofertada aos povos do campo, começou a ser transformada a partir da luta dos trabalhadores organizados em movimentos sociais que demandaram uma educação diferenciada, de acordo com a sua realidade camponesa. Nasce, assim, a Educação do Campo, que não cabe no atual modelo hegemônico de escola da sociedade capitalista, porque ela molda o ser humano à passividade e o conduz à subordinação.

É nesse cenário que Santos (2017) destaca que a organização do trabalho pedagógico na Escola do Campo parte do pressuposto de que a vida campesina ensina além da escola formal, e de que a Educação só faz sentido se elevar a consciência das populações do campo e estas encontrarem condições de mudar a sociedade. Com essa premissa, a autora advoga a favor da inclusão da Educação Ambiental na Escola do Campo, e afirma que a Educação Ambiental Campesina demarca o perfil ideal da Educação Ambiental no contexto da Escola do Campo, representando uma promissora ferramenta para os educadores que propõem ações e reflexões contra hegemônicas nas Escolas do Campo ampliarem sua atuação, interagindo com uma dimensão da vida campesina intrínseca do processo de luta por mudanças nas relações sociais nas escolas e comunidades: a temática ambiental.

A Educação Ambiental Campesina estimula a visão comparativa entre o agronegócio latifundiário e a agricultura de base agroecológica, problematiza a forma de produzir alimentos capaz de assegurar a proteção ambiental, identifica conflitos socioambientais no campo, denuncia a degradação ambiental como queimadas, desmatamento, poluição por agrotóxicos e resíduos agroindustriais, além de atuar de forma a preservar e ampliar as áreas protegidas e respectivos serviços ecossistêmicos na propriedade rural. A Educação Ambiental Campesina contribui, em essência, com o fortalecimento do senso de pertencimento dos sujeitos do campo com a natureza, revelando os agricultores camponeses como autênticos ecologistas interessados e qualificados para atuar na luta ambiental que combate as forças desenvolvimentistas propulsoras da conversão do uso do solo no campo a favor da expansão do agronegócio latifundiário sobre as florestas (SANTOS, 2017).

$\mathrm{O}$ artigo Justiça, racismo e conflitos ambientais na literatura sobre educação ambiental: o que dizem os anais dos encontros nacionais de pesquisa em educação ambiental?, de Michele Alice da Silva, Angélica Cosenza e Vicente Paulo dos Santos Pinto (2017), objetiva compreender como vem sendo pensada a Educação Ambiental em sua relação com a justiça, o racismo e os conflitos ambientais. Os autores, inicialmente, pontuam que a preocupação ambientalista contemporânea reconhece que as inúmeras modificações ambientais resultam de um processo de expropriação do meio ambiente e dos modos de sobrevivência de diversos sujeitos e coletivos, tornando-os socioambientalmente vulneráveis, 
com sua autonomia ameaçada. O direito à água tratada, saneamento, áreas verdes, ar limpo, recursos naturais e serviços ecossistêmicos íntegros, são alguns atributos ambientais que se distribuem de maneira desigual nos diferentes grupos sociais, e sua negação evidencia uma clara violação de direitos humanos, principalmente daqueles que vivem nas zonas de sacrifício da expansão capitalista.

O movimento por Justiça Ambiental trouxe, como legado para o debate ecológico, o ideal de justiça social. Nesse contexto, os autores selecionaram os artigos que fazem referência aos termos Conflito Ambiental, Justiça Ambiental e Racismo Ambiental, no título, resumo e/ou palavras-chave nas publicações do EPEA em suas oito edições: verifica-se, ao longo do tempo, um aumento do número de artigos que articulam a Educação Ambiental com a Justiça Ambiental, embora nem todos aprofundem e problematizem os processos de desigualdade socioambiental. Mas apesar desse aumento, constatou-se haver ainda uma quantidade inexpressiva no número de artigos que exploram a interface da Educação Ambiental com a Justiça Ambiental, e os autores creditam que esse frágil vínculo é um reflexo da debilidade do debate da relação entre desigualdade social e exposição ao risco ambiental no campo da Educação Ambiental (SILVA; COSENZA; PINTO, 2017).

Porém, com o registro de treze trabalhos no ano de 2015, a oitava edição do EPEA, surpreendentemente, testemunhou um notável aumento do número de artigos focando a temática da Justiça Ambiental, contrastando com a média de três artigos em cada edição anterior. Segundo os autores, esse súbito aumento retrata a intensa transformação de conceitos e práticas que ocorreu no período recente no campo da Educação Ambiental, que pode ser indicativo de um expressivo amadurecimento teórico em curso, onde o ideal da justiça social e dos direitos humanos conquista um lugar mais destacado na Educação Ambiental.

$\mathrm{O}$ artigo Justiça ambiental nas teses e dissertações de educação ambiental, de Thaís Angeli e Luiz Marcelo de Carvalho (2017), por sua vez, caracteriza o contexto brasileiro de produção das teses e dissertações em Educação Ambiental (concluídas entre 1981 e 2014 e catalogadas no Banco de Teses e Dissertações do Projeto EArte), também em que a Justiça Ambiental é centralmente problematizada.

Os autores asseveram que, no contexto da Educação Ambiental Crítica, é pressuposto que o modo de produção capitalista esteja no centro do debate pedagógico; e assim, entre as questões que têm sido postas pela perspectiva crítica da Educação Ambiental, destaca-se a relação entre o modo de produção econômica e a desigualdade socioambiental. Dessa forma, argumentam Angeli e Carvalho (20017), colocar a injustiça ambiental no debate pedagógico significa contribuir com o desvelamento das assimetrias de poder e os mecanismos de opressão que perpetuam as desigualdades socioambientais, o que representa um potencial incentivo à mobilização da população para uma perspectiva crítica acerca da temática ambiental. Assim, os autores frisam que a internalização da temática da Justiça Ambiental na Educação Ambiental contribui com a abertura de outros caminhos para a constituição de sociedades socialmente justas e ecologicamente equilibradas.

Nesse contexto, 23 teses e dissertações foram analisadas: dezessete delas foram desenvolvidas em programas de pós-graduação da grande área de Ciências Humanas, sendo doze na área de Educação, três na Psicologia, uma na Geografia e uma na Sociologia. Cinco foram desenvolvidas em programas de pós-graduação da grande área Multidisciplinar, sendo dois na área de Ensino de Ciências e Matemática, uma nas Ciências Ambientais, uma na Engenharia/Tecnologia/Gestão e uma em Meio Ambiente e Agrárias. Um trabalho foi desenvolvido em um programa de pós-graduação da grande área de Ciências Biológicas, na área de Ecologia. A Universidade Federal de Mato Grosso, juntamente com a pesquisadora Michèle Sato, teve grande representatividade nas teses e dissertações analisadas, o que está 
diretamente relacionado com o foco do Grupo Pesquisador em Educação Ambiental, Comunicação e Arte, cuja referida pesquisadora é uma de suas líderes.

O primeiro trabalho de Educação Ambiental que aborda a Justiça Ambiental foi publicado em 2004 e, a partir desse ano, a distribuição temporal seguiu relativamente estável, não sendo observada grande diferença no número de trabalhos produzidos ao longo dos anos.Quanto à distribuição geográfica, as regiões Sudeste, Sul e Centro-Oeste destacam-se na produção acadêmica. Os autores lembram, ainda, que ainda persistem análises a serem realizadas sobre a especificidade da relação entre Justiça Ambiental e Educação Ambiental.

$\mathrm{O}$ artigo Movimentos sociais e educação ambiental: um panorama da pesquisa em Educação Ambiental em teses e dissertações brasileiras, de Larissa Nobre Magacho e Rosa Maria Feiteiro Cavalari (2017), investiga as relações entre Movimentos Sociais e a Educação Ambiental estabelecidas nas teses e dissertações em Educação Ambiental. As autoras constataram que as áreas de concentração e os programas de pós-graduação nos quais são desenvolvidas as pesquisas analisadas não diferem significativamente das pesquisas panorâmicas realizadas no campo da Educação Ambiental: expressam alta diversidade de áreas e programas, mas com destaque para as áreas de Educação e Ciências Ambientais.

O Nordeste, que geralmente ocupa a penúltima posição na produção acadêmica de Educação Ambiental por região, ainda que com apenas uma pesquisa a mais que o Sudeste, neste caso, ocupa a primeira posição. As autoras creditam que essa situação pode estar relacionada ao Programa Regional de Pós-Graduação em Desenvolvimento e Meio Ambiente, um programa interinstitucional presente em várias universidades federais da região nordeste.

Magacho e Feiteiro (2017) ressaltam que, a partir da resistência aos riscos ambientais emergem movimentos sociais específicos, que lutam por Justiça Ambiental. Consideram haver uma ampla gama de informações ainda a serem analisadas nessas teses e dissertações, que podem fornecer subsídios que possibilitem a construção de caminhos a serem percorridos no campo de pesquisa da Educação Ambiental em sua perspectiva crítica, rumo à maior aproximação e diálogo com os movimentos sociais.

\section{O encontro presencial do GDP Educação Ambiental e Movimentos Sociais}

Em agosto de 2017, durante o IX EPEA, após as sessões de apresentação e discussão de pesquisa, ocorreram dois encontros presenciais do GDP Educação Ambiental e Movimentos Sociais. Nesses dois momentos, além de estarmos reunidos presencialmente com pesquisadores da área, pudemos dialogar sobre as temáticas prevalentes e emergentes da pesquisa em Educação Ambiental.

Motivados pela reflexão coletiva a partir de algumas questões iniciais que pautaram o debate sobre os nexos entre os Movimentos Sociais e a Educação Ambiental, a temática ambiental e sua abordagem no processo educativo intrínseco à luta dos Movimentos Sociais, o perfil político-pedagógico das práticas de Educação Ambiental e demais características identitárias que conferem especificidade a essa relação, os participantes do encontro presencial problematizaram cinco aspectos: o perfil particular da Educação presente no âmbito dos Movimentos Sociais, o limitado alcance dos saberes produzidos pelos Movimentos Sociais, a boa relação entre a extensão universitária e os Movimentos Sociais, a necessidade de ampliação do diálogo entre a Escola e os Movimentos Sociais, e a agenda de pesquisa militante junto aos Movimentos Sociais.

\subsection{O perfil da Educação presente nos Movimentos Sociais}


O primeiro aspecto levantado foi sobre a natureza da Educação existente no âmbito dos Movimentos Sociais. A Educação formal que se deseja no seio dos Movimentos Sociais é uma educação conquistada, fruto da luta cidadã pelo direito à educação escolar, entendido como parte integrante da luta sociopolítica dos Movimentos Sociais. Mas a Educação formal que se pratica no seio dos Movimentos Sociais é, também, uma educação diferenciada, distinta da unidimensionalidade padronizada das bases curriculares pertencentes à realidade moderna urbano-industrial com seus tempos e lógicas ancoradas na cultura capitalista, porque é referenciada no seu contexto territorial específico, é adaptada à conjuntura sociopolítica particular daquele grupo social.

Há, também, uma dimensão pedagógica implícita nas práticas dos Movimentos Sociais, onde aparecem as oportunidades de aprendizagem coletiva, uma educação informal inerente ao processo da luta política, aquela educação que se expressa seja no aprendizado da experiência política da mobilização social pela defesa de uma causa coletiva na esfera pública; seja inerente à dimensão da vida cotidiana de povos tradicionais, onde a rotina do trabalho coletivo se mescla com a convivência e interação diária entre crianças, jovens e adultos: vivendo e lutando, os ativistas dos Movimentos Sociais são produtores de saberes úteis à manutenção daquele estilo de vida ou à elaboração de estratégias de resistência e mobilização política.

Com os saberes produzidos pelos Movimentos Sociais e com a prática da militância, é uma Educação que evolui com a aprendizagem ao longo da própria luta política, mesclando o legítimo direito de pertencimento àquele território ameaçado ou degradado com o direito de construir democraticamente políticas públicas de grande envergadura que imprimam outro sentido ao desenvolvimentismo capitalista.

É uma Educação de base comunitária, que aprofunda o senso de pertencimento comunitário a um dado território, fortalecendo o nexo coletivo orgânico com o Movimento Social ao longo do processo de defesa ou conquista de direitos sociais e humanos.

É uma Educação marcada pela posição contra-hegemônica, subversiva a uma ordem social opressora e injusta, que parte do princípio do combate à injustiça e desigualdade, e que habilita comunidades vulneráveis e em risco para a atuação política na esfera pública, canalizando as estratégias de mobilização e controle social, exercida pelos próprios grupos, por meio de uma pedagogia da resistência.

É uma Educação que adota instrumentos pedagógicos alternativos e que promove novas formas de pensar o território, de modo mais abrangente, considerando suas relações com o racismo, a injustiça e a desigualdade, como o Toxic Tour, o cinema ambiental freireano, a participação em audiências públicas.

É uma Educação que, por compartilhar de princípios orientadores e leituras conjunturais comuns, se articula com a Educação Popular, a Educação em Direitos Humanos, a Educação do Campo e a Educação Ambiental Crítica, e possui vínculos viscerais com a Justiça Ambiental - o recorte temático específico da pauta ambiental pela perspectiva dos Movimentos Sociais - embora o grupo avalie que, apesar da afinidade, ainda há espaço para se desenvolver uma aproximação mais orgânica.

\subsection{O fraco alcance dos saberes produzidos pelos Movimentos Sociais}

A despeito de toda riqueza da educação protagonizada pelos Movimentos Sociais, o limitado alcance da condição pedagógica dos Movimentos Sociais como autênticos produtores de saberes foi o segundo aspecto destacado no GDP. Reconhecendo que há casos em que os saberes produzidos pelos Movimentos Sociais acabam sendo pouco divulgados, os 
participantes alertaram para a importância da sistematização e socialização das experiências de diálogo entre a comunidade acadêmica e os Movimentos Sociais, destacando, em especial, as contribuições dessa colaboração para a Educação Ambiental de caráter político e transformador.

Caberia, nesse sentido, lançar mão de novas formas de comunicação, potencializando a divulgação e apropriação desses saberes por iniciativas de Educação Ambiental em contextos de conflito e resistência. Isto poderia ocorrer através da comunicação alternativa e contra-hegemônica, explorando as redes sociais e seus processos participativos por meio de uma visão politizadora, para além do controle midiático convencional, acentuando-se a liberdade de expressão e a convergência de ideias e valores afins entre os movimentos. Tratase, como asseveram Moraes, Ramonet e Serrano (2013) de incluir estes grupos em um ecossistema virtual, descentralizado e interativo, questionador das práticas assentadas na mídia corporativa e potencializador da dimensão educativa dos Movimentos Sociais.

\subsection{O agregador diálogo entre a extensão universitária e os Movimentos Sociais}

O terceiro aspecto destacado durante o GDP foi o caráter agregador das atividades de extensão universitária, que aproximam os docentes e estudantes de diferentes níveis aos membros de Movimentos Sociais e moradores de comunidades atingidas. Para os participantes, essas iniciativas, especialmente quando atreladas a projetos de pesquisa, podem contribuir para ampliar a denúncia das injustiças e para criar novos espaços formativos, incluindo também a Escola. Segundo Paula (2013, p. 6) a extensão convoca "a universidade para o aprofundamento de seu papel como instituição comprometida com a transformação social, que aproxima a produção e a transmissão de conhecimento de seus efetivos destinatários", corrigindo assimetrias na apropriação social do conhecimento, cultura e tecnologias.

\subsection{O tímido diálogo entre a Escola e os Movimentos Sociais}

O quarto aspecto ressaltado referiu-se à importância de haver uma maior aproximação entre as experiências educacionais desenvolvidas pelos Movimentos Sociais e os processos formativos de estudantes e professores da educação básica na Escola. Muitas iniciativas de Educação Ambiental Crítica que se articulam aos Movimentos Sociais, notadamente aquelas engajadas nas lutas ambientais ou que procuram empoderar os sujeitos para a atuação política, acabam sendo promovidas em espaços da Educação Popular, da Educação do Campo, em Resistência Urbana, em projetos de extensão universitária e até mesmo no âmbito dos próprios Movimentos Sociais.

Entre os treze textos enviados ao GDP, apenas dois descreviam propostas de Educação Ambiental articuladas, de algum modo, com o sistema formal de ensino, as quais ocorreram por meio da formação de professores. Nesse sentido, percebe-se que a Educação proposta pelos Movimentos Sociais ainda pode ampliar seu campo de ação, estreitando os laços com comunidades escolares das redes pública e privada, em especial aquelas vulnerabilizadas por situações de injustiça ambiental.

De forma semelhante, é interessante notar que na edição anterior, em 2015 (LAYRARGUES; PUGGIAN, 2016), interrogou-se até que ponto a Escola, especialmente aquela situada em zonas de sacrifício, tem abordado a temática do Conflito Socioambiental em suas ações de Educação Ambiental, apontando, inclusive, a importância de se estabelecer alguma articulação entre o GDP Movimentos Sociais e o GDP Contexto Escolar do EPEA, 
para que seja possível analisar a relação entre Escola e Justiça Ambiental/Movimentos Sociais presente e debatida no âmbito desse outro GDP.

Está colocada, novamente, a questão de se a Escola está tematizando pedagogicamente os casos de conflitos ambientais em suas respectivas áreas de influência, mas não nos textos, e, sim, no encontro presencial. A maioria dos textos do GDP examinou ou fez referência a experiências educativas realizadas fora do ambiente escolar. Percebe-se que o debate pedagógico sobre Justiça Ambiental, Movimentos Sociais e Territorialidades - entre outros temas - apresentam-se distantes do sistema público de ensino, como se comunidades e escolas estivessem inseridas em realidades distintas, em territórios distantes.

\subsection{Horizontes da agenda de pesquisa engajada com os Movimentos Sociais}

Por fim, o quinto aspecto destacado pelos participantes diz respeito ao universo da agenda de pesquisa que se apresenta aberta na relação entre Movimentos Sociais e Educação Ambiental, observando alguns parâmetros analíticos, como os processos de autodeterminação dos territórios, a autogestão da educação formal e as epistemologias não hegemônicas. As discussões do GDP consideraram, também, a existência de intelectuais nativos como autores dessa pauta de pesquisa, ou seja, sujeitos oriundos de grupos atingidos que se forjaram academicamente, tendo como eixo epistemológico a luta ambiental. E, ainda, as múltiplas possibilidades de pertencimento de educadores ambientais, docentes, pesquisadores, estudantes e ativistas de Movimentos Sociais, cujos papeis sociais podem ser desempenhados simultaneamente.

Acentuaram ainda que é preciso manter coerência entre a teoria e os procedimentos metodológicos adotados durante as investigações, onde se destacam as metodologias participativas e militantes.

Entre algumas questões de pesquisa levantadas pelo grupo, ressalta-se: Os Movimentos Sociais tem se apropriado dos resultados das pesquisas produzidas no campo da Educação Ambiental? A Educação Ambiental está produzindo um conhecimento útil à luta política socioambiental dos Movimentos Sociais? Quais são as formas de divulgação das pesquisas produzidas no campo da Educação Ambiental que as tornam acessíveis para os Movimentos Sociais? Até que ponto a Educação Ambiental está contribuindo com a visibilidade e dignidade dos sujeitos em torno dos Movimentos Sociais, ocultados, desprezados ou criminalizados pelos meios midiáticos convencionais? Quais são os referenciais conceituais adotados sobre a pesquisa engajada na perspectiva decolonial latinoamericana?

\section{Signos de uma Educação Ambiental a partir dos Movimentos Sociais}

O exame dessas obras nos permitiu identificar um conjunto de signos que podem ser úteis para contribuir com a caracterização da Educação Ambiental a partir dos Movimentos Sociais no quadro do GDP na IX edição do EPEA, em 2017.

Destacaram-se, nesta análise, seis aspectos: a centralidade essencial que o ato pedagógico confere à Justiça Ambiental no conjunto do repertório temático explorado pela Educação Ambiental, a renovação do compromisso da macrotendência político-pedagógica Crítica com o estabelecimento de vínculos com os Movimentos Sociais, a Pedagogia da Resistência como a ideia-força estruturante da Educação Ambiental realizada pelos Movimentos Sociais, o amadurecimento do recente campo de pesquisa cuja especificidade está na análise científica da relação entre Educação Ambiental e Movimentos Sociais, a noção 
de Direitos Humanos como uma contribuição dos Movimentos Sociais que enriqueceu a práxis da Educação Ambiental e reciprocamente, o desvelamento das silenciadas lutas dos Movimentos Sociais como a colaboração da Educação Ambiental e, finalmente, as perspectivas que se abrem com o potencial diálogo entre a Educação Ambiental e a Geografia Crítica, apontando para novas convergências na Ecologia Política.

\subsection{A centralidade da temática da Justiça Ambiental no ato pedagógico militante}

São os Movimentos Sociais, mais do que qualquer outro setor da comunidade ambientalista, os sujeitos sociais que, no território, opõem resistência às injustiças socioambientais advindas com o avanço da fronteira do desenvolvimentismo capitalista, portanto, é natural que a Justiça Ambiental se constitua como a abordagem central das práticas de Educação Ambiental no âmbito dos Movimentos Sociais.

Essa temática traz em si um universo de significados próprios que passam a integrar o repertório conceitual do campo da Educação Ambiental, o que por sua vez contribui com a definição dessa especificidade identitária da Educação Ambiental que emerge dos Movimentos Sociais.

O engajamento político-pedagógico da Educação Ambiental encontra simetria no movimento em defesa dos direitos humanos que, segundo Jean-Pierre Leroy $(2011$, p. 1) somente avança e se concretiza na forma da lei "quando setores sociais oprimidos ou explorados conseguem fazer entender a sociedade, pela persuasão e até pela violência, a profunda injustiça que eles estão sofrendo". Isto significa que, no âmbito dos conflitos, é o grito dos oprimidos, é a sua força e dedicação à construção de relações menos desiguais, do contraponto à visão mercadológica da natureza, que vão abrindo espaços para outras visões de futuro, não somente para eles, mas para todos. Suas lutas pela conservação da biodiversidade, pela mitigação das mudanças climáticas, pela preservação dos rios e florestas, pelo fechamento de depósitos clandestinos de resíduos, pelo saneamento básico, pelo banimento da indústria agroquímica, pela criação de reservas extrativistas, pelo direito à cidade, entre tantas bandeiras, fazem com que a relação dos povos com a natureza exceda os limites de dependências materiais e simbólicas, inscrevendo-se, também, no campo dos direitos humanos.

É nesse contexto que o movimento por Justiça Ambiental torna-se uma referência crucial $^{4}$ para os trabalhos submetidos ao GDP. Como já identificado na edição anterior (LAYRARGUES; PUGGIAN, 2016), a temática da Justiça Ambiental é absolutamente central para os Movimentos Sociais; ou seja, o enquadramento natural pelo qual os Movimentos Sociais operam no amplo conjunto da comunidade ambiental partilha da perspectiva do ambientalismo popular e situa-se na lógica do socioambientalismo.

Acselrad (2010) argumenta que a noção de Justiça Ambiental permite que novos significados sejam atribuídos à questão ambiental, reapropriada por meio de dinâmicas tradicionalmente atreladas à promoção da justiça social. Segundo esse autor, no caso brasileiro, as lutas por Justiça Ambiental combinam:

- a defesa dos direitos a ambientes culturalmente específicos - comunidades tradicionais situadas na fronteira da expansão das atividades capitalistas e de mercado;

- a defesa dos direitos a uma proteção ambiental equânime contra a segregação socioterritorial e a desigualdade ambiental promovidas pelo mercado;

\footnotetext{
${ }^{4}$ Entre os treze trabalhos submetidos ao IX GDP, oito referenciaram as contribuições de Acselrad e colaboradores, confirmando uma tendência que já se esboçava anteriormente.
} 
- a defesa dos direitos de acesso equânime aos recursos ambientais, contra a concentração das terras férteis, das águas e do solo seguro nas mãos dos interesses econômicos fortes no mercado[...];

- a defesa dos direitos das populações futuras (ACSELRAD 2010, p.114).

A articulação entre as lutas atuais e os direitos futuros ocorreria pela interrupção da destinação injusta dos danos ambientais às populações mais pobres e vulnerabilizadas. $\mathrm{Ou}$ seja, o movimento por Justiça Ambiental mostra que para interromper a destruição do ambiente para todos, é preciso começar criando estratégias de defesa para os mais fracos, superando a desigualdade social. Nessa perspectiva, parte-se da premissa de que enquanto não houver um ambiente saudável para um ser humano poder viver, hoje, com dignidade no planeta, há dúvidas que a humanidade seja realmente capaz de atender ao preceito do Desenvolvimento Sustentável - satisfazer as necessidades atuais sem comprometer as gerações futuras. Como garantir o legado de um ambiente saudável para o futuro se o modelo desenvolvimentista contemporâneo sequer é capaz de assegurar, hoje, um ambiente saudável para todos?

É por esse prisma, do combate à injustiça socioambiental, da mescla entre Direitos Humanos e Justiça Ambiental, que os Movimentos Sociais partilham com a comunidade ambiental a busca pela sustentabilidade: a partir da perspectiva da defesa de um ambiente ameaçado, mas que, ao mesmo tempo, é também a base de sustentação da vida de povos tradicionais na floresta ou do campo, ou é condição de saúde e qualidade de vida de cidadãos marginalizados no contexto urbano-industrial. É quando não apenas as condições ambientais estão sendo degradadas, é também quando essas condições ambientais degradadas refletem negativamente sobre as condições de vida dos humanos.

Mas não de qualquer ser humano, porque como pela perspectiva dos Movimentos Sociais a questão ambiental é atravessada pela luta de classes, se observa a relação de forças entre capital e trabalho entranhada também na luta ambiental, onde o trabalho representa a categoria que passa a defender a natureza enquanto base material e simbólica de sustentação de determinados grupos sociais populares, natureza essa ameaçada pelo poder do capital em seu processo de expansão e acumulação. O grito dos oprimidos é a voz agonizante de uma natureza invadida, sufocada e saqueada, pedindo socorro. É o alarme da insustentabilidade alertando o colapso da base natural de sustentação da vida, que explorada e degradada, condenando incontáveis grupos sociais à servidão da miséria humana nas periferias.

\section{2 É a perspectiva político-pedagógica Crítica do campo da Educação Ambiental que assume o compromisso do vínculo com os Movimentos Sociais}

O lugar institucional da fala, a partir da qual se apresenta o estudo acerca da relação entre Educação Ambiental e Movimentos Sociais, é o da macrotendência político-pedagógica Crítica (LAYRARGUES; LIMA, 2014), aquela que, por definição, possui entre seus fundamentos a reflexão e o envolvimento nos processos de luta e resistência anticapitalista contra a injustiça, racismo, opressão e desigualdade socioambiental, aquela que consegue enxergar a luta de classes se expressando na arena ambiental, na medida em que o processo de apropriação do território e da natureza pelo capital implica na reprodução do sistema capitalista. Não foi todo o campo genericamente da Educação Ambiental, mas, sim, a perspectiva Crítica que assumiu a responsabilidade do envolvimento político-pedagógico no combate à injustiça ambiental.

Nesse sentido, narrando as experiências dos sujeitos e comunidades em luta, esse lugar institucional específico visibiliza as ocultadas lutas políticas demarcadas pelos conflitos 
socioambientais, revelando as assimetrias de poder na sociedade. Compromete-se com a análise das relações desiguais, solidarizando-se com os grupos afetados pelas injustiças, embora cumpre ressaltar que nenhum texto teve autores que também fossem membros dos Movimentos Sociais, caracterizando o quadro da pesquisa engajada ou ativista. Nota-se haver, ainda, um distanciamento dos Movimentos Sociais, que não foram representados no GDP: esse singular espaço de reflexão sobre a relação entre a Educação Ambiental e os Movimentos Sociais, por enquanto ainda não é de convergência entre pesquisadores/educadores ambientais e ativistas militantes dos Movimentos Sociais.

\subsection{A Pedagogia da Resistência como ideia-força da Educação Ambiental praticada pelos Movimentos Sociais}

Diz-se popularmente que acostumar-se é outra forma de morrer. Ao longo dos anos, a Educação Ambiental construída em diálogo com os Movimentos Sociais, por meio de processos político-pedagógicos críticos e emancipadores, tem-se dedicado a denunciar a naturalização das desigualdades, o silenciamento dos conflitos sociais, a criminalização das lutas por direitos humanos e as formas de expropriação dos territórios e modos de vida tradicionais.

Nessa trajetória destaca-se a indubitável compreensão do ato educacional como um ato político, em que o educador-educando engaja-se abertamente no diálogo e na superação da situação-limite que oprime o trabalhador (FREIRE, 2001), combinando o anúncio de outra perspectiva de vida autônomo fora do desenvolvimentismo economicista, e a denúncia desse modelo insustentável de desenvolvimento capitalista (FREIRE, 2000). Vários estudos já examinaram a influencia das obras de Paulo Freire na Educação Ambiental Crítica e emancipatória (LOUREIRO; TORRES, 2014), o que também temos observado nos trabalhos submetidos ao GDP Educação Ambiental e Movimentos Sociais ao longo dos anos.

Como desígnio da tarefa educadora constante nos Movimentos Sociais, ganha corpo uma Pedagogia da Resistência, ou seja, uma pedagogia que estimula a adoção da postura contra-hegemônica dentro de uma luta sociopolítica, de conquista de direitos, mas de natureza subversiva e contestatória contra uma ordem social injusta, onde o sacrifício das condições ecológicas de sustentação da Vida também compromete grupos sociais populares e povos tradicionais. É o genuíno exercício da ecocidadania, a formação ecopolítica para a participação comunitária popular em processos de controle social cidadão.

Aqui, a Educação Ambiental cumpre um papel bem distinto daquele que se verifica fora do enquadramento da Educação Ambiental Crítica: a prevalência do estímulo à ação coletiva na esfera pública, em detrimento do massificado estímulo à ação individual na esfera privada, proporcionado pelas perspectivas conservadoras de Educação Ambiental. Não foca na responsabilização individual da clássica fórmula liberal de cada um fazer a sua parte, mas habilita o educando a interagir com processos democráticos na construção de direitos humanos e na limitação da opressão ambiental.

Estimula o senso de pertencimento local e o envolvimento comunitário, mas não a uma biofilia genérica à natureza, e, sim, junto àqueles que se encontram em condições de injustiça socioambiental, fundamento para o engajamento ativo na mobilização em defesa do território ameaçado.

Aqui, se confere a preocupação com o olhar pedagógico ecopolítico a ser assumido pela Educação Ambiental, destacando-se a necessidade de problematizar a ocupação e uso do território que geram não apenas problemas ambientais, mas também conflitos ambientais que refletem fielmente a desigualdade social e as injustas relações de poder. A análise político- 
pedagógica não se restringe, apenas, na caracterização do impacto ambiental em si, com seus fatores e processos biofísico-químicos, mas, também, como e porque esse impacto ambiental afeta desigualmente grupos sociais em posições hierárquicas inferiores no tecido social.

A mediação pedagógica da Educação Ambiental, demarcada pela Pedagogia da Resistência, promove a reflexão sobre as causas estruturais da degradação/injustiça socioambiental, estimula a compreensão da conjuntura histórica política e econômica da insustentabilidade da sociedade capitalista, buscando a maior clareza no entendimento da inerente insustentabilidade dos determinantes desenvolvimentista-econômico.

Essa Educação Ambiental praticada pelos Movimentos Sociais definitivamente não foi cooptada pelo ambientalismo pragmático de mercado, e possui um perfil completamente distinto de uma Educação Ambiental Capitalista (LAYRARGUES, 2018), por não ter se constituído numa educação instrumentalizada e reprodutivista, subserviente ao capital, e ter guardado coerência com o espírito da transformação social.

Talvez, a melhor formulação conceitual que defina a natureza dessa Educação Ambiental a partir dos Movimentos Sociais seja a formulada por Stortti e Sánchez (2017), intitulada Educação Ambiental Decolonial de Base Comunitária. Aí reside a dimensão educadora intrínseca à dinâmica da luta ecopolítica dos Movimentos Sociais: a rica experiência da pedagogia da resistência no território de pertencimento ancestral e coletivo, transborda para a experiência da formulação de políticas públicas de envergadura nacional, ousando pensar em projetos desenvolvimentistas alternativos ao capital, a exemplo dos caminhos empreendidos pela lógica do Buen Vivir não mais apenas entre povos tradicionais andinos, mas, também, inscrita na carta constitucional de dois países latino-americanos, Equador e Bolívia.

\subsection{O amadurecimento do recente campo de investigação acadêmica sobrea relação entre Educação Ambiental e Movimentos Sociais}

Como registrado no VIII EPEA, os participantes do GDP continuam buscando apoio nas teorias críticas, no Marxismo e na Ecologia Política. Agora, porém, surge com força o pós-colonialismo como outro campo conceitual que oferece contribuições à fundamentação teórica de subsídio às intervenções educadoras dos Movimentos Sociais quando envolve a temática ambiental.

Tal como na edição anterior, prossegue o esforço da explicitação dos vínculos da Educação Ambiental no âmbito de algumas frações dos Movimentos Sociais, com a educação diferenciada para os distintos contextos, como os povos tradicionais, a educação na cidade e a educação no campo, explorando as similaridades e sinergias, indicando um aprofundamento conceitual em aspectos muito particulares, como a definição dos contornos de uma Educação Ambiental Campesina ou de uma Educação Ambiental Decolonial de Base Comunitária.

A IX edição do EPEA também recebeu pesquisas dedicadas à análise de instrumentos pedagógicos aplicados pelos Movimentos Sociais em suas intervenções em Educação Ambiental. Se o cinema ambiental ganhou destaque na edição passada, as audiências públicas e os observatórios de conflitos ambientais foram objeto de reflexão nesta edição, apresentados como alternativas pedagógicas apropriadas para a reflexão sobre a relação entre capital, degradação ambiental, miséria humana e território.

O IX EPEA abrigou uma expressiva produção intelectual, analisando os registros acadêmicos de pesquisas em torno da relação entre Educação Ambiental, Justiça Ambiental e Movimentos Sociais, denotando a existência de uma preocupação com o estudo da 
especificidade e das características da Educação Ambiental desenvolvida pelos Movimentos Sociais.

A meta é compreender e sistematizar a produção de conhecimento recentemente acumulado em busca da compreensão das lógicas implícitas dessa Educação Ambiental que não é a mesma desenvolvida na maioria das escolas, dos governos e tampouco nas organizações não governamentais ambientalistas estrito senso, e, certamente, não nas empresas; e que apenas recentemente começa a ser explorado, ao contrário da longa tradição de pesquisa da relação da Educação Ambiental com a escola, a empresa, a política pública, que antecede até mesmo a Conferência do Rio em 1992. É a organização do campo em curso, se reconhecendo, aprofundando seus fundamentos teóricos e seus princípios orientadores, criando narrativas explicativas, sondando alianças com outros setores, estabelecendo pactos e compromissos, explorando outras alternativas pedagógicas, se avaliando.

\subsection{Os recíprocos legados do encontro entre Educação Ambiental e Movimentos Sociais: Justiça Social e Direitos Humanos, mas, também, visibilidade}

Já se percebe que a Educação Ambiental foi modificada em função da influência da aproximação junto aos Movimentos Sociais. Convidada pelo compromisso com o movimento de Justiça Ambiental, o encontro com a militância socioambiental de Movimentos Sociais engajados na luta contra a Desigualdade Socioambiental, colocou em contato dois princípios muito centrais que balizam a atuação dos Movimentos Sociais, que são a Justiça Social e os Direitos Humanos.

O encontro da Educação Ambiental com os Movimentos Sociais trouxe, como herança, o aprofundamento da compreensão de dois conceitos estruturantes para se pensar no ato pedagógico pautado pelos conflitos socioambientais. Começam a surgir análises e processos na Educação Ambiental que falam a língua dos Direitos Humanos, vínculo que não parecia muito presente até pouco tempo atrás. Direitos Humanos e Justiça Social começam a aparecer como elementos éticos balizadores de reflexões e programas de Educação Ambiental.

Por outro lado, os Movimentos Sociais ganharam na sua luta ecopolítica um importante parceiro na tarefa de desmascarar a tentativa de oprimir, ocultar, menosprezar e criminalizar a mobilização política em torno das bandeiras do ecologismo de base popular. Ao trazer a problematização político-pedagógica da Justiça Ambiental, a Educação Ambiental colabora enormemente com a ampliação do grito sufocado dos afetados pela injustiça e opressão socioambiental: faz a mediação com uma ampla audiência e acrescenta visibilidade e transparência sobre as assimétricas e injustas relações de poder.

\subsection{Novas convergências na Ecologia Política: o despertar do diálogo entre Educação Ambiental e Geografia Crítica?}

Prossegue o chamamento ao campo da Educação Ambiental para que a análise ambiental pela perspectiva político-pedagógica seja empreendida com a compreensão da totalidade do território. O território não apenas nos seus elementos constituintes relacionados à dimensão ecológica ou físico-química própria das ciências da Vida, mas o território também na sua dimensão sociocultural e econômica, onde seja possível ao ato pedagógico efetuar a reflexão sobre a relação entre os seres humanos e a natureza a partir de outros parâmetros, quer seja, considerando as relações de poder existentes nas sociedades de classe organizadas pelo modo de produção capitalista. 
É com a análise dessa dimensão da relação entre a sociedade e a natureza, quando aparecem os sujeitos históricos em suas distintas posições sociais e em seus territórios, que será permitido ao educando compreender que não existem apenas impactos ambientais, mas também injustiças ambientais correlacionadas aos impactos ambientais. Se o caminho da sustentabilidade, necessariamente, passa pela superação do capitalismo, não basta estimular apenas as mediações técnicas e gerenciais de gestão ambiental para um bom sujeito ecológico, mas, também, estimular o enfrentamento comunitário da desigualdade socioambiental especialmente nas zonas de sacrifício urbano-industrial, do campo e da floresta.

A Geografia Crítica não aparece, objetivamente, nos trabalhos e reflexões efetuadas no GDP do IX EPEA, mas enquanto um campo científico fundamentado na crítica à sociedade capitalista, a partir da análise das formas de apropriação e uso do espaço, do território, e da natureza, parece promissor explorar a convergência entre a Geografia Crítica e essa Educação Ambiental Decolonial de Base Comunitária que emerge na luta ecopolítica dos Movimentos Sociais, pois pode oferecer mais um ângulo na leitura conceitual da problemática que delimita a defesa do território e a resistência contra o desenvolvimentismo capitalista.

Indicativo dessa aproximação é a constatação de três trabalhos que buscaram referenciar suas balizas conceituais na obra de Milton Santos, uma importante referência na Geografia Crítica muito pouco presente na Educação Ambiental.

\section{Referências}

ACSELRAD, H. Ambientalização das lutas sociais: o caso do movimento de justiça ambiental. Estudos Avançados, São Paulo, v. 24, n.68, p. 103-120. 2010.

ANGELI, T.; CARVALHO, L.M. de. Justiça ambiental nas teses e dissertações de educação ambiental. In: ENCONTRO DE PESQUISA EM EDUCAÇÃO AMBIENTAL, 9, 2017, Juiz de Fora. Anais... Juiz de Fora: UFJF, 2017.

AQUINO, M.G. de C.; LOUREIRO, Y.V.M.; STORTTI, M.A. A justiça e o racismo ambiental diante do rompimento da Barragem de Fundão (Mariana - MG): A educação ambiental de base comunitária e os movimentos sociais diante da problemática econômica e ambiental em torno da mineração. In: ENCONTRO DE PESQUISA EM EDUCAÇÃO AMBIENTAL, 9, 2017, Juiz de Fora. Anais... Juiz de Fora: UFJF, 2017.

ARAÚJO, S.D.; SGARBI, A.D.; LOBINO, M. das G. Educação Ambiental e Movimentos Sociais: um contributo ao enraizamento da Educação Ambiental na cidade de Vitória/ES. In: ENCONTRO DE PESQUISA EM EDUCAÇÃO AMBIENTAL, 9, 2017, Juiz de Fora. Anais... Juiz de Fora: UFJF, 2017.

CAMPOS, B.F. Educação Ambiental, Direito à Moradia e à Cidade e Movimentos Sociais, o Exemplo do Rio de Janeiro.In: ENCONTRO DE PESQUISA EM EDUCAÇÃO AMBIENTAL, 9, 2017, Juiz de Fora. Anais... Juiz de Fora: UFJF, 2017.

DELEUZE, G.; GUATTARI, F. Mil platôs: capitalismo e esquizofrenia. Vol. 3. Rio de Janeiro: Editora 34, 1996.

FREIRE, P. Política e Educação. 5 ed. São Paulo: Cortez, 2001.

FREIRE, P. Pedagogia da Indignação: cartas pedagógicas e outros escritos. São Paulo: Editora Unesp, 2000. 
LAYRARGUES, P.P.; LIMA, G. F. da C. As macrotendências político-pedagógicas da educação ambiental brasileira. Ambiente e Sociedade, São Paulo, v.17, n.1, p.23-40. jan./mar. 2014.

LAYRARGUES, P.P.; PUGGIAN, C. Convergências na Ecologia Política: Quando a Educação Ambiental abraça a luta por Justiça Ambiental. Pesquisa em Educação Ambiental, Rio Claro, v.11, n.2, p.72-82, jul./dez. 2016.

LAYRARGUES, P.P. Educação Ambiental nas Sociedades Capitalistas. Novamerica, Rio de Janeiro, n.157, p.24-30, jan./mar. 2018.

LEROY, J.P. Justiça ambiental. Portal do GESTA - Grupo de Estudos em Temáticas Ambientais [online]. Belo Horizonte: GESTA, 2011. Disponível em: <http://conflitosambientaismg.lcc.ufmg.br/wp-content/uploads/2014/04/TAMC-LEROY_Jean-

Pierre_-_Justi\%C3\%A7a_Ambiental.pdf>. Acesso em: 9 maio 2018.

LEROY, J.P. Territórios do futuro: educação, meio ambiente e ação coletiva. Rio de Janeiro: Lamparina, 2010.

LOUREIRO, C. F.; TORRES, J. R. (Orgs.) Educação ambiental: dialogando com Paulo Freire. São Paulo: Cortez, 2014.

KASSIADOU, A.; SÁNCHEZ, C.; RENAUD, D. Os observatórios de conflitos ambientais como instrumentos pedagógicos para fortalecer práticas e pesquisas em Educação Ambiental.In: ENCONTRO DE PESQUISA EM EDUCAÇÃO AMBIENTAL, 9, 2017, Juiz de Fora. Anais... Juiz de Fora: UFJF, 2017.

MAGACHO, L.N.; FEITEIRO, R.M. Movimentos sociais e educação ambiental: um panorama da pesquisa em EA em teses e dissertações brasileiras. In: ENCONTRO DE PESQUISA EM EDUCAÇÃO AMBIENTAL, 9, 2017, Juiz de Fora. Anais... Juiz de Fora: UFJF, 2017.

MORAES, D.; RAMONET, I.; SERRANO, P. Mídia, poder e contrapoder: da concentração monopólica à democratização da comunicação. São Paulo: Boitempo, 2013.

PAULA, J.A. de. A extensão universitária: história, conceito e propostas. Interfaces: Revista de Extensão da UFMG, Belo Horizonte, v.1, n.1, p.5-23, jul./nov. 2013.

SANTOS, E.M. dos. A formação de educadores do campo em educação ambiental: a importância da formação continuada de educadores ambientais campesinos na UFMT. In: ENCONTRO DE PESQUISA EM EDUCAÇÃO AMBIENTAL, 9, 2017, Juiz de Fora. Anais... Juiz de Fora: UFJF, 2017.

SCHLESINGER, M.T.; GARCIA, J.J.P.; MAYRINK, L. da S. Os megaeventos na cidade do Rio e Janeiro e a Educação Ambiental: reflexões a partir dos impactos e conflitos gerados pelas disputas territoriais. In: ENCONTRO DE PESQUISA EM EDUCAÇÃO AMBIENTAL, 9, 2017, Juiz de Fora. Anais... Juiz de Fora: UFJF, 2017.

SILVA, M.A. da; COSENZA, A.; PINTO, V.P. dos S. Justiça, racismo e conflitos ambientais na literatura sobre educação ambiental: o que dizem os anais dos encontros nacionais de pesquisa em educação ambiental? In: ENCONTRO DE PESQUISA EM EDUCAÇÃO AMBIENTAL, 9, 2017, Juiz de Fora. Anais... Juiz de Fora: UFJF, 2017. 
SOUZA, V.M. de; LOUREIRO, C.B. Povos tradicionais caiçaras e a demanda pela educação escolar: aproximações com a educação ambiental crítica. In: ENCONTRO DE PESQUISA EM EDUCAÇÃO AMBIENTAL, 9, 2017, Juiz de Fora. Anais... Juiz de Fora: UFJF, 2017.

SPALA, M.; PEÇANHA, A.L. Educação Ambiental e Audiência Pública sobre Coleta Seletiva e Reciclagem do Resíduo Óleo Vegetal em Alegre - ES. In: ENCONTRO DE PESQUISA EM EDUCAÇÃO AMBIENTAL, 9, 2017, Juiz de Fora. Anais... Juiz de Fora: UFJF, 2017.

STORTTI, M.A.; SÁNCHEZ, C. Educação Ambiental Decolonial de Base Comunitária: a Pedagogia dos afetados pelo setor da mineração. In: ENCONTRO DE PESQUISA EM EDUCAÇÃ̃O AMBIENTAL, 9, 2017, Juiz de Fora. Anais... Juiz de Fora: UFJF, 2017.

VIEIRAS, R.R.; SEPULCRI, N.; TRISTÃO, M. A existência em pauta: uma problematização a partir do crime socioambiental na bacia do rio Doce. In: ENCONTRO DE PESQUISA EM EDUCAÇÃO AMBIENTAL, 9, 2017, Juiz de Fora. Anais... Juiz de Fora: UFJF, 2017. 